\title{
Modeling of atmospheric freeze-drying for sliced fruits
}

\section{Horie, A. ${ }^{\text {a }}$ Kobayashi, T..$^{\text {; }}$ Nakagawa, K. ${ }^{\text {* }}$}

a Division of Food Science and Biotechnology, Graduate School of Agriculture, Kyoto University, Sakyo-ku Kitashirakawa Oiwakecho, Kyoto 606-8502, Japan

*E-mail of the corresponding author: kyuya@kais.kyoto-u.ac.jp

\begin{abstract}
A mathematical model that simulates atmospheric freeze-drying for apple slices was developed based on the classical mass and heat balance equations. When operated above the glass transition temperature, product shrinkage and micro-collapse due to the glass-rubber transition occurred. So, instead of assuming formation of dried and frozen zones, a glassy matrix with particular vapor pressure was assumed. Apparent vapor pressure of apple slices in the glassy state was experimentally measured and summarized in a diagram, and the values in this diagram were employed for the simulation. This approach well predicted drying kinetics with reasonable accuracy with simplified equations.
\end{abstract}

Keywords: atmospheric freeze-drying; food; mathematical model; glassy state 


\section{Introduction}

Freeze-drying is known as one of the best drying methods in terms of preservation of product qualities. Vacuum freeze-drying (VFD) process is widely implemented in food and pharmaceutical industries, and variations of products are commercialized. Atmospheric freeze-drying (AFD) is basically equivalent to vacuum freeze-drying, where the ice sublimation is the major dehydration mechanism. The water vapor pressure difference between the frozen zone and the ambient gas is the driving force of the mass transfer. In order to operate drying at below sub-zero temperature, the air humidity must be low at appropriate level. A heat-pump system is commonly used to make low humidity air. The condenser temperature of the heat-pump unit is necessarily set lower than the product temperature during drying, and the dehumidified air must properly be heated up to realize appropriate drying rate. Numbers of studies on AFD process were motivated to optimize this heat-pump drying system in terms of the energy consumption and drying rate. ${ }^{[1-4]}$

Drying temperature (air temperature) applied for AFD is usually at around -10 to $0^{\circ} \mathrm{C}$. So, the product temperature during drying, that could be several degrees lower than the drying temperature depending on the drying rate, is much higher than the case of VFD. When drying agricultural products, a typical AFD run places the products above their glass transition temperatures $\left(T^{\prime}{ }_{\mathrm{g}}\right)$. For example, the $T^{\prime}{ }_{\mathrm{g}}$ value of strawberry ranges from -33 to $-41^{\circ} \mathrm{C}$, that of apple is at around $-42^{\circ} \mathrm{C}$, and peach at around $-36^{\circ} \mathrm{C} \cdot{ }^{[5]}$ Considering that the drying rate is not rapid as the case of a hot air drying, product temperature could be several degree below the air temperature that is far above the glass transition temperature. At this temperature, the product deformation such as shrinkage and/or micro-collapse occur as a consequence of the glass-rubber/ glass-liquid transitions. In such cases, the dried cake layer, that commonly forms during a typical freeze-drying run, does not clearly separate from the frozen zone. In order to simulate this drying system, it is necessary to develop a model that is different from commonly employed two zone models consisted with frozen and dry zones.

In this study, mathematical model that simulates atmospheric freeze-drying for apple slices was developed. This study was targeted for an atmospheric freeze-drying process operated far over the glass transition temperature of the products, where we must admit the product deformation such as shrinkage and micro-collapse due to glass-rubber transition.

\section{Mathematical Model}

A product placed in the atmospheric freeze-dryer is dried by convective air. A product (i.e. a slice of apple) has porous structures derived from cellular microstructures. The external and some parts of the inner pore surfaces contact to the external air flow. Whereas, the other parts of the surfaces contribute to the convection with the internal air flow (Fig. 1). The surface that contributes to the internal convection is written with the total product surface, namely: 
$A_{\text {in }}=\gamma A_{\text {total }}$

Here, $\gamma$ is the coefficient that gives the surface that is not influenced by the convective air. The surface that effectively contributes to the external convection can be written as:

$A_{\text {eff }}=(1-\gamma) A_{\text {total }}$

The mass transfer equation of the vaporized water vapor can be written with the mass transfer coefficients of the external and internal boundary layers, namely:

$\frac{d m}{d t}=\frac{P_{\mathrm{i}} / T_{\mathrm{i}}-{ }^{P_{\text {air }} / T_{\text {air }}}}{1 /(1-\gamma) A_{\text {total }} k_{\text {gex }}+1 / \gamma A_{\text {total }} k_{\text {gin }}} \frac{M}{R}$

The heat transfer equation can be written with the heat transfer coefficients of the external and internal boundary layers:

$Q=\frac{T_{\mathrm{i}}-T_{\text {air }}}{1 /(1-\gamma) A_{\text {total }} h_{\mathrm{ex}}+{ }^{1} / \gamma A_{\text {total }} h_{\text {in }}}$

Assuming that the system is at a quasi-steady state, the heat flow is balanced with the mass flow.

$Q / \Delta H=\frac{d m}{d t}=\frac{P_{\mathrm{i}} / T_{\mathrm{i}}{ }^{P_{\text {air }} / T_{\text {air }}}}{1 /(1-\gamma) A_{\text {total }} k_{\text {gex }}+{ }^{1} / \gamma A_{\text {total }} k \text { gin }} \frac{M}{R}=\frac{T_{\mathrm{i}}-T_{\text {air }}}{1 /(1-\gamma) A_{\text {total }} h_{\text {ex }}+{ }^{1} / \gamma A_{\text {total }} h_{\text {in }}} \frac{1}{\Delta H}$

The solution of this equation provides the value of $T_{\mathrm{i}}$. The calculation was performed with spreadsheet software (Microsoft Excel ${ }^{\circledR}$ ) by non-linear regression using solver add-in. It should be noted that the water vapor pressure $P_{\mathrm{i}}$ at the temperature $T_{\mathrm{i}}$ was given as a function of the moisture content of product as the detail explained in the later section.
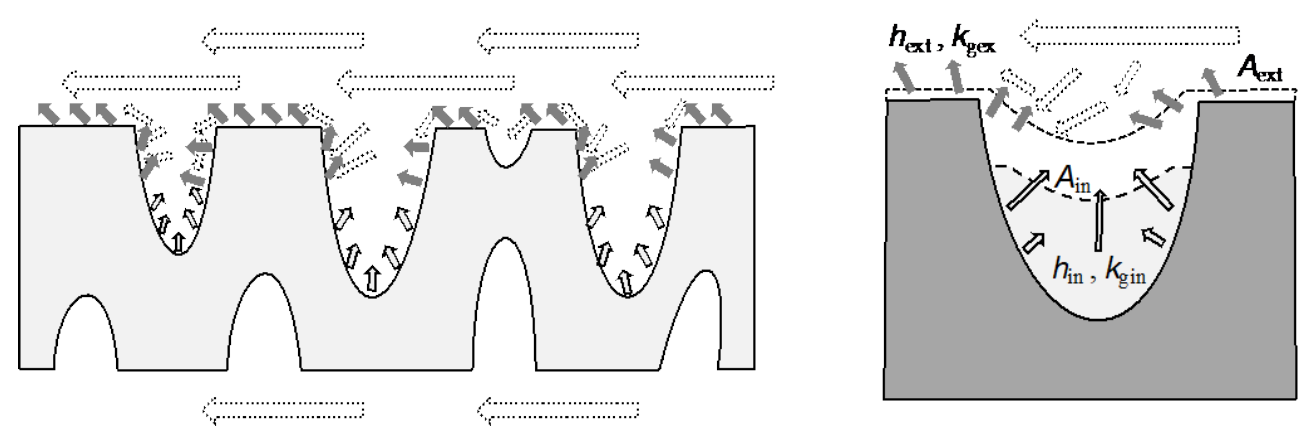

Fig. 1 Schematic illustration of AFD model. 


\section{Materials and Methods}

\subsection{Atmospheric freeze-drying}

The atmospheric freeze-dryer that composed with a condenser and heating devise was set-up as schematized in Fig. 2. The condenser temperature was set at around $-30^{\circ} \mathrm{C}$, and the outgas temperature could be controlled by the heating devise in the range of -20 to $5^{\circ} \mathrm{C}$. The air flow rate in the drying room was controlled by an electric fan in the range of 0.1 to $0.5 \mathrm{~m} / \mathrm{s}$. Four slices of apple $(15 \times 15 \times 5 \mathrm{~mm})$ were set in a plastic tray and suspended from a load-cell (A\&D, Japan). The weight loss during drying was monitored with the load-cell. Apple slices were first frozen with the convective air at $-30^{\circ} \mathrm{C}$, and then the air temperature was increased at a selected heating rate from -10 to $5^{\circ} \mathrm{C}$ and the weight loss was recorded with data logging system.

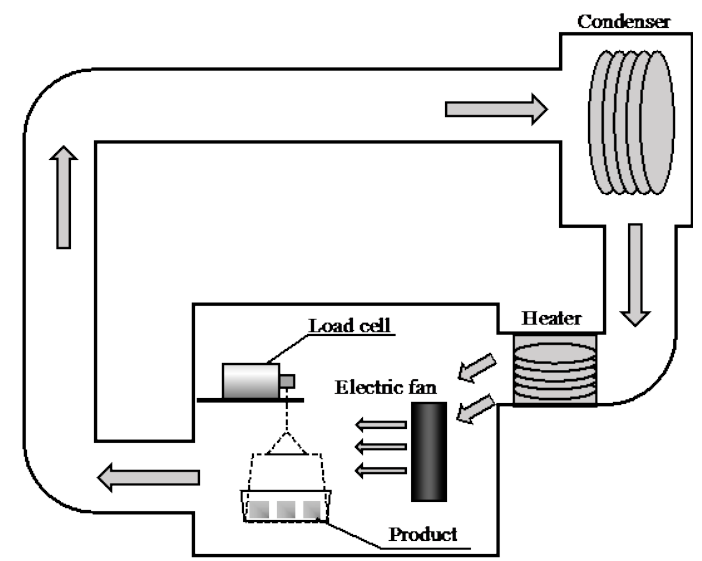

Fig. 2 Drying apparatus.

\subsection{Ice sublimation test}

The ice sublimation test was conducted in order to determine mass and heat transfer coefficients. Distilled water was filled in a plastic tray and frozen in the devise. Weight losses were monitored at selected temperature and air velocity settings. The temperature of the sublimating ice $\left(T_{\mathrm{p}}\right)$ and the sublimation rate $(\mathrm{dm} / \mathrm{dt})$ were collected with the selected operating conditions. The obtained values were applied to Equation 5 to estimate $k_{\text {gex }}$ and $h_{\text {ex }}$ values by applying $A_{\text {in }}=0, A_{\text {ex }}=A_{\text {total }}$.

\subsection{Measurement of apparent water vapor pressure of apple slice}

The use of apparent water vapor pressure as a function of the temperature and moisture content was a key part of this study. The relationship among these parameters were determined by the pressure rise test with a specially designed experimental set as illustrated 
in Fig. 3. An apple slice was first vacuum freeze-dried, and then placed in a desiccator with a solution saturated with various salts $\left(\mathrm{LiCl}, \mathrm{MgCl}_{2}, \mathrm{KNO}_{3}\right.$ and $\left.\mathrm{Mg}\left(\mathrm{NO}_{3}\right)_{2}\right)$ in order to humidify the dried product. The moisture content of the humidified sample was measured by a moisture meter (A\&D, Japan), and the other portion was set in the sample room and the measurement devise was immersed in a cooling bath of which temperature was set at a selected temperature in the range of -30 to $0^{\circ} \mathrm{C}$. The external room that was separated with a bellows valves was first evacuated with a rotary type vacuum pump. After stabilizing the temperature and pressure, the bellows valve was rapidly opened for 2-3 seconds and immediately closed. The pressure rise due to the vaporization was monitored for 1 hour with a pirani gauge that was set in the sample room.

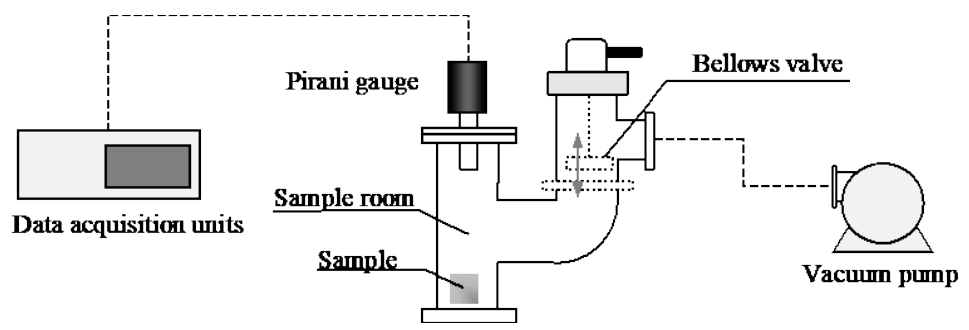

Fig. 3 Pressure rise measurement set-up.

\section{Results and Discussions}

\subsection{Apparent water vapor pressure of apple slices}

Some selected results of the pressure rise test were shown in Fig. 4. One can clearly see that the pressure rose just after opening the bellows and stabilized at a certain pressure level. Fig. 4A shows the dependency of the vapor pressure on the temperature; the pressure, as expected, was higher at higher temperature. However, the absolute values of the pressure were significantly lower than the equilibrium vapor pressure value of pure water. It means that several hours was not enough for the system to reach at an equilibrium state. Fig. 4B suggested that the time required for reaching at an equilibrium state was greatly affected by the moisture content of the apple slice; the apparent vapor pressure was higher for the sample with higher moisture content. The effective vapor pressure that a product shows during drying could be the pressure that was measured by the pressure rise test. We thus employed the value of the pressure from the pressure rise test at the point of 1 hour, and the values were plotted as a function of temperature and solid content (converted from the moisture content value). As summarized in a diagram in Fig. 5, this is a key characteristic of the present apple that is distinguished from the other products showing different drying kinetics. The solid line in the diagram correspond to the glass transition line; the closer the glass transition line, the apparent vapor pressure significantly decreases. 

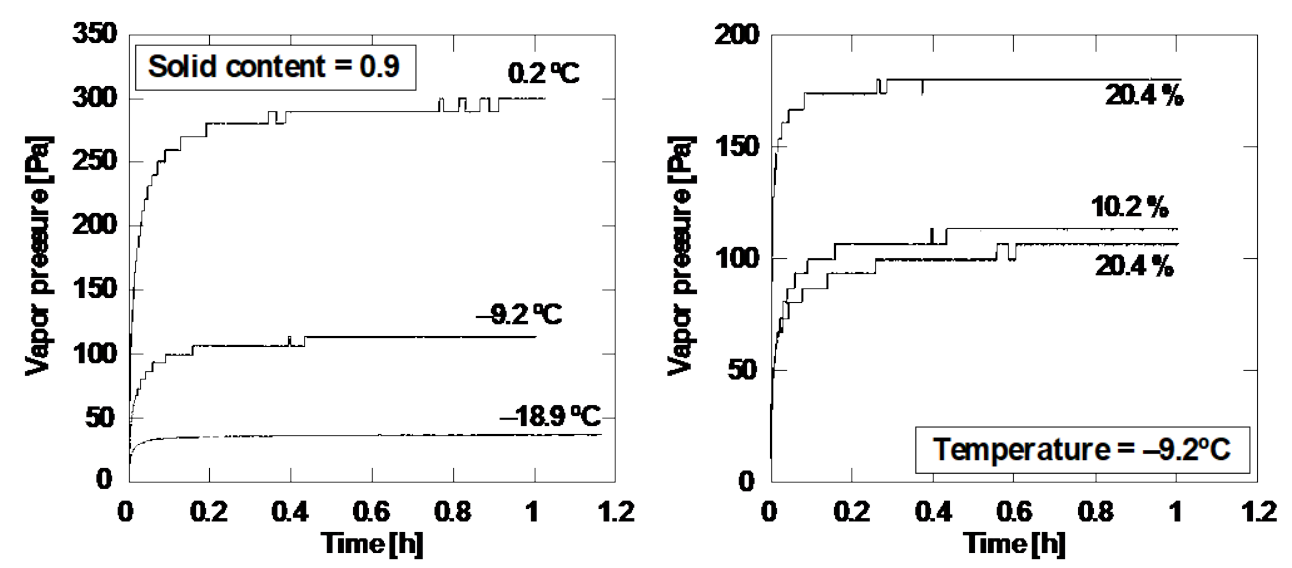

Fig. 4 Pressure rise of apple slice under sub-zero temperature.

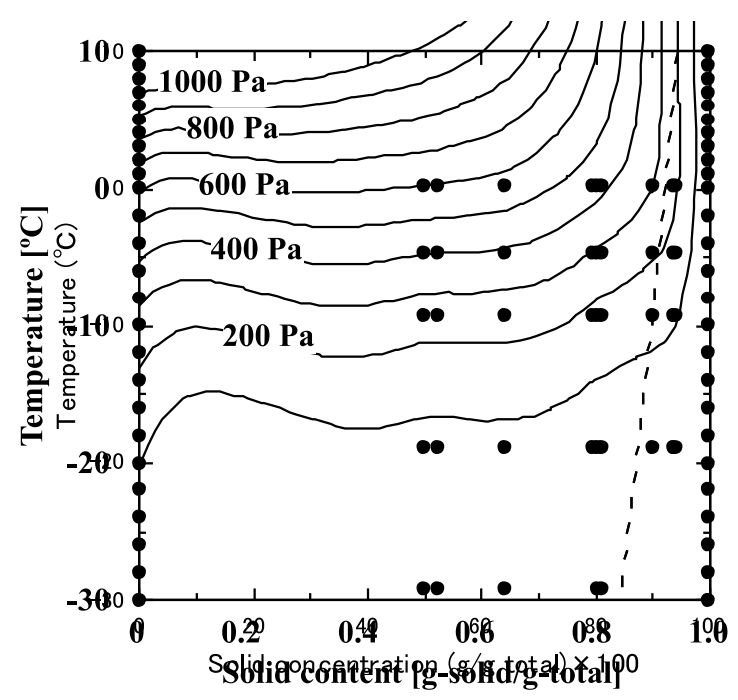

Fig. 5 Apparent water vapor pressure contour lines as a function of temperature and solid content.

\subsection{Freeze-drying run}

A result of the atmospheric freeze-drying run is shown in Fig. 6. The air flow temperature was operated as shown in this figure by the present drying apparatus, and the consequence of the weight loss was plotted in the same figure. Air temperature was programmed to increase as the progress of drying in order to reduce total drying time. A simulation was carried out based on the mathematical model by applying the experimentally obtained air flow temperature. The water vapor pressure value, that is dependent on the temperature and 
moisture content, was estimated from the surface plots shown in Fig. 5 by applying a simulated product temperature and moisture content values. The parameters applied for the simulation were listed in Table 1. The simulated drying curve is compared in Fig. 6 with the experimental curve. It was obvious that the simulation well predicts the experimental drying kinetics. The present simulation is based on a mechanistic mathematical model, so it simultaneously gives the other important values such as product temperature, mass and heat flow rates, etc. The simulated product temperature during drying plotted in Fig. 6 suggested that the drying progressed far above the glass transition temperature of apple, so some phenomena that may occur in a rubbery system (e.g. shrinkage, micro-collapse) are not avoidable in this drying system. The simulation could thus be more accurate by introducing a variable drying surface area instead of mean total surface area $\left(A_{\text {total }}\right)$ and mass transfer coefficient values $\left(k_{\text {gin }}\right)$. The air temperature was well programed to realize the driving force for heat transfer until the final stage of the drying. This simulation approach would be useful to design favorable drying protocol.

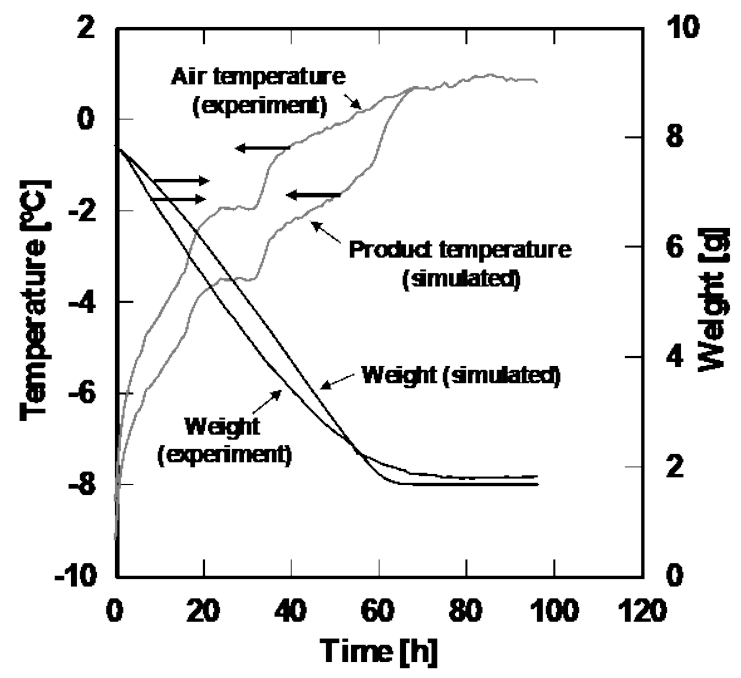

Fig. 6 Drying curves; comparison between experimental and simulated curves

Table 1. Parameters for simulation

\begin{tabular}{ll||ll}
\hline \multicolumn{1}{c}{ Parameter } & \multicolumn{1}{c}{ Value } & \multicolumn{1}{c}{ Parameter } & \multicolumn{1}{c}{ Value } \\
\hline$A_{\text {total }}\left[\mathrm{m}^{2}\right]$ & $9.7 \times 10^{-2}$ & $h_{\text {gex }}\left[\mathrm{Wm}^{-2} \mathrm{~K}^{-1}\right]$ & 49.2 \\
$\gamma[-]$ & 0.99 & $h_{\text {gin }}\left[\mathrm{Wm}^{-2} \mathrm{~K}^{-1}\right]$ & 13.7 \\
$k_{\text {gex }}\left[\mathrm{ms}^{-1}\right]$ & $1.01 \times 10^{-2}$ & $P_{\text {air }}[\mathrm{Pa}]$ & 104.9 \\
$k_{\text {gin }}\left[\mathrm{ms}^{-1}\right]$ & $1.47 \times 10^{-2}$ & $R\left[\mathrm{~J} \mathrm{~mol}{ }^{-1} \mathrm{~K}^{-1}\right]$ & 8.314 \\
$\Delta H\left[\mathrm{~J} \mathrm{~kg}^{-1}\right]$ & $2.4 \times 10^{6}$ & $T_{\text {air }}[\mathrm{K}]$ & 253 \\
$M\left[\mathrm{~kg} \mathrm{~mol}^{-1}\right]$ & $1.8 \times 10^{-2}$ & & \\
\hline
\end{tabular}




\section{Conclusions}

A mathematical model that simulates atmospheric freeze-drying for sliced fruits was developed and applied to apple slice drying. Apparent vapor pressure of the apple slice was measured by the pressure rise test and the obtained values were summarized in a diagram. The pressure values were dependent on the temperature and moisture content; the closer the glass transition line, the apparent vapor pressure significantly decrease. Simulations carried out with this diagram well predict drying kinetics with reasonable accuracy with simplified equations.

\section{Nomenclature}

$\begin{array}{lll}A_{\text {total }} & \text { total surface area } & \mathrm{m}^{2} \\ \gamma[-] & \text { inner surface ratio } & - \\ k_{\text {gex }} & \text { mass transfer coefficient } & \mathrm{ms}^{-1} \\ k_{\text {gin }} & \text { mass transfer coefficient } & \mathrm{ms}^{-1} \\ \Delta H & \text { latent heat of vaporization } & \mathrm{J} \mathrm{kg}^{-1} \\ h_{\text {gex }} & \text { heat transfer coefficient } & \mathrm{Wm}^{-2} \mathrm{~K}^{-1} \\ h_{\text {gin }} & \text { heat transfer coefficient } & \mathrm{Wm}^{-2} \mathrm{~K}^{-1} \\ M & \text { molar mass of water } & \mathrm{kg} \mathrm{mol}^{-1} \\ m & \text { mass of product } & \mathrm{kg} \\ P_{\text {air }} & \text { water vapor pressure in the air flow } & \mathrm{Pa} \\ P_{\mathrm{i}} & \text { water vapor pressure at the drying interface } & \mathrm{Pa} \\ Q & \text { heat flow } & \mathrm{J} \mathrm{s} \\ R & \text { ideal gas constant } & \mathrm{J} \mathrm{mol} \\ T_{\text {air }} & \text { temperature of the air flow } & \mathrm{K} \\ T_{\mathrm{i}} & \text { temperature at the drying interface } & \mathrm{K} \\ t & \text { time } & \mathrm{s}\end{array}$

\section{References}

[1] Alves-Filho, O. Combined Innovative Heat Pump Drying Technologies and New Cold Extrusion Techniques for Production of Instant Foods. Drying Technology 2002, 20, 1541-1557.

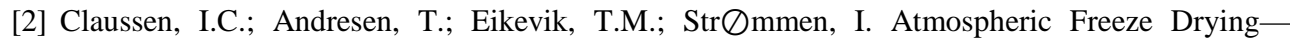
Modeling and Simulation of a Tunnel Dryer. Drying Technology 2007, 25, 1959-1965.

[3] Wolff, E.; Gibert, H. Atmospheric freeze-drying part 1: Design, experimental investigation and energy-saving advantages. Drying Technology 1990, 8, 385-404.

[4] Claussen, I.C.; Ustad, T.S.; Str $\oslash$ mmen, I.; Walde, P.M. Atmospheric Freeze Drying-A Review. Drying Technology 2007, 25, 947-957.

[5] Slade, L.; Levine, H.; Reid, D.S. Beyond water activity: Recent advances based on an alternative approach to the assessment of food quality and safety. Critical Reviews in Food Science and Nutrition 1991, 30, 115-360. 